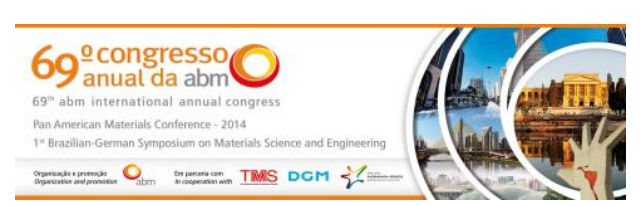

Tema: Materiais Cerâmicos, Compósitos e Poliméricos

\title{
CARACTERIZAÇÃO DE ARGAMASSAS PARA PROTEÇÃO RADIOLÓGICA*
}

\section{Resumo}

Frieda Saicla Barros ${ }^{1}$ Gustavo Macioski

Argamassas feitas com cimento são comumente usadas para revestimentos de paredes, pisos e tetos. Para proteção radiológica, estas argamassas são acrescidas de pó de bário, elemento atenuante contra radiações ionizantes. Este trabalho tem como objetivo principal comparar argamassas usuais utilizadas como revestimento de paredes com a argamassa baritada, cuja finalidade é proteção radiológica em ambientes sujeitos a radiação ionizante. Com base no objetivo proposto, estabeleceu-se a metodologia do trabalho constituída das seguintes etapas: caracterização dos materiais constituintes das argamassas por meio dos ensaios de análise química por fluorescência de raios- $X$, análise granulométrica, determinação das densidades experimental pelo método de pesagem e medição volumétrica manual dos corpos de prova, moldagem dos corpos de prova das argamassas normais e argamassa baritada (material comumente utilizado para proteção radiológica), avaliação das propriedades mecânicas e avaliação da atenuação da radiação $X$ utilizando o programa Xcom. Por meio deste programa, foram simulados os coeficientes de atenuação em massa das composições, gerando curvas de atenuação, no intervalo de energia estimado a cada 0,01 keV. Em função destas curvas de atenuação em massa, verificou-se o desempenho das argamassas comparando-as com outros materiais desenvolvidos e com materiais de referência (chumbo).

Palavras-chave: Argamassa; Barita; Raios-X; Proteção radiológica.

\section{Abstract}

\section{CHARACTERIZATION OF MORTAR TO RADIATION PROTECTION}

Mortars made with cement are commonly used for wall cladding, floors and ceilings. For radiological protection, these mortars are added with powdered barium that is a mitigating factor against ionizing radiation. This study aims to compare the usual mortars used as wall cladding with barium mortar, whose purpose is to radiological protection in environments subject to ionizing radiation. Based on the proposed objective, we established the methodology of the work consists on the following steps: characterization of the constituent materials of mortar through the trials of chemical analysis by X-ray fluorescence, particle size analysis, determination of experimental densities by the method of weighing and measuring manual volume of specimens, molding of test specimens of normal mortars and barium mortar (material commonly used for radioprotection), assessment and evaluation of the mechanical properties of the radiation attenuation using the program Xcom. Through this program, the mass attenuation coefficients of the compositions were simulated; generating attenuation curves in the energy range ships each $0.01 \mathrm{keV}$. Depending on these mass attenuation curves, there was performance of the mortars comparing them with reference material (lead).

Keywords: Mortar; Barite; X-ray; Radiation protection.

1 Engenheira Civil, Doutorado, Professora, DAFIS, PPGEB, Universidade Tecnológica Federal do Paraná, Curitiba, PR, Brasil.

2 Aluno do Curso de Engenharia Civil, Universidade Federal do Paraná, Curitiba, PR, Brasil.

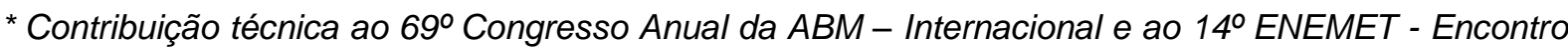
Nacional de Estudantes de Engenharia Metalúrgica, de Materiais e de Minas,21 a 25 de julho de 2014, São Paulo, SP, Brasil.
} 


\section{INTRODUÇÃO}

De acordo com Carasek [1], as argamassas são materiais empregados na construção civil, sendo os seus principais usos no assentamento de alvenarias. Argamassa, segundo a NBR 13281:2001 [2], é uma mistura homogênea de agregado(s) miúdo(s), aglomerante(s) inorgânico(s) e água, contendo ou não aditivos ou adições, com propriedades de aderência e endurecimento, podendo ser dosada em obra ou em instalação própria (argamassa industrializada).

A principal função da argamassa é transmitir todas as ações atuantes, de forma a solidarizar as unidades, criando uma estrutura única. Outras funções que deve exercer são a acomodação das deformações e a compensação das irregularidades das peças [3].

$O$ revestimento das paredes e tetos com argamassa tem a finalidade de: proteger a alvenaria e a estrutura contra a ação de intemperismo, no caso dos revestimentos externos; integrar o sistema de vedação dos edifícios, contribuindo com acústico ( $\approx 50 \%$ ), estanqueidade à água (70 a $100 \%$ ), segurança ao fogo e resistência ao desgaste e abalos superficiais; regularizar a superfícies dos elementos de vedação e servir como base para acabamentos decorativos, contribuindo para a estética da edificação [1].

Visando satisfazer às funções citadas anteriormente, algumas propriedades tornamse essenciais para essas argamassas, a saber: retração; aderência; permeabilidade à água; resistência mecânica, principalmente a superficial e capacidade de absorver deformações.

A argamassa baritada é um composto de areia, cimento e aglomerante, podendo ter como agregado a barita, um minério de alta densidade, ou o sulfato de bário hidratado $\left(\mathrm{BaSO}_{4}\right)$ utilizada como revestimento de superfícies sujeitas a radiação ionizante.

$\mathrm{Na}$ área da construção civil, a argamassa para revestimento feita na obra apresenta uma variedade na sua composição, referente à quantidade dos materiais constituintes da mesma (agregado miúdo, cal, cimento e às vezes incorporação de fibras) [4]. Também existe uma variedade de marcas comerciais de argamassas baritadas, função da quantidade de barita na mistura resultando em uma alta densidade, absorvendo mais radiação. Sua aplicação na área de proteção radiológica se dá pelo custo do produto, comparado ao valor das lâminas de chumbo, sem precisar de mão-de-obra especializada. A aplicação desta argamassa se dá da mesma maneira que a argamassa tradicional.

Diferentes materiais podem ser estudados como alternativa as lâminas de chumbo [5] e a argamassa baritada [6], disponíveis comercialmente, além de haver ainda a possibilidade de desenvolvimento de novos tipos de materiais, tais como: os polímeros [7,5], os cerâmicos [8] e os compósitos poliméricos misturados com óxido de chumbo $[9,10]$.

Este trabalho tem como objetivo principal comparar argamassas usuais utilizadas como revestimento de paredes com a argamassa baritada, material usado para proteção radiológica, bem como suas propriedades de atenuação, aplicando o programa computacional Xcom [11] para determinar as propriedades de atenuação.

Foram feitas a caracterização dos materiais constituintes da argamassa por meio dos ensaios de análise química por fluorescência de raios $X$, análise granulométrica, determinação das densidades experimental pelo método de pesagem e medição volumétrica manual dos corpos de prova; moldagem dos corpos de prova de argamassa e argamassa baritada (material comumente utilizado para proteção

\footnotetext{
* Contribuição técnica ao $69^{\circ}$ Congresso Anual da ABM - Internacional e ao 14ํㅡㄹ ENEMET - Encontro Nacional de Estudantes de Engenharia Metalúrgica, de Materiais e de Minas,21 a 25 de julho de 2014, São Paulo, SP, Brasil.
} 


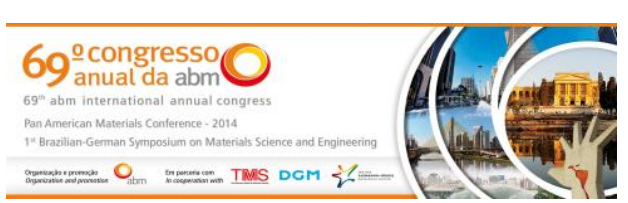

radiológica), avaliação das propriedades mecânicas e avaliação da atenuação da radiação X utilizando o programa Xcom [11]. Utilizando-se este programa, podem-se simular coeficientes de atenuação das argamassas de acordo com a metodologia do trabalho de Frimaio $[8,5]$ e construir curvas de atenuação em massa no intervalo na energia estimada de $0,01 \mathrm{keV}$. Em função destas curvas de atenuação em massa, verificou-se o desempenho das argamassas comparando-as com o material mais utilizado, ou seja, laminas de chumbo.

\section{MATERIAIS E MÉTODOS}

Para a confecção das argamassas normais foram utilizados: Cimento Portland, cal hidratada, agregado miúdo, água e fibras de vidro. Como material de comparação foi também avaliado um lote de argamassa baritada comercial.

\subsection{Cimento Portland}

Para as argamassas dosadas em laboratório foi utilizado o CPII-Z 32 da marca Itambé, que leva, em sua composição, de 6 a 14\% de pozolana. As características físicas e químicas destes materiais foram obtidas diretamente com o fabricante, bem como a sua massa específica de $2.97 \mathrm{~g} / \mathrm{cm}^{3}$. As Tabelas 1 e 2 apresentam as características químicas e físicas do cimento adotado.

Tabela 1. Características Químicas do Cimento Itambé - CPII-Z 32

\begin{tabular}{c|c|c|c|c|c|c|c|c|c}
\hline \multicolumn{1}{c}{ Características Químicas } \\
\hline $\begin{array}{c}\text { Al2O3 } \\
(\%)\end{array}$ & $\begin{array}{c}\mathrm{SiO} 2 \\
(\%)\end{array}$ & Fe2O3(\%) & $\begin{array}{c}\mathrm{CaO} \\
(\%)\end{array}$ & $\begin{array}{c}\mathrm{MgO} \\
(\%)\end{array}$ & $\begin{array}{c}\mathrm{SO} \\
(\%)\end{array}$ & $\begin{array}{c}\mathrm{Fog} \\
(\%)\end{array}$ & $\begin{array}{c}\mathrm{CaO} \text { L. } \\
(\%)\end{array}$ & $\begin{array}{c}\text { R. Ins. } \\
(\%)\end{array}$ & $\begin{array}{c}\text { Eq. } \\
\text { Alc. } \\
(\%)\end{array}$ \\
\hline 6,35 & 22,41 & 2,96 & 53,76 & 4,00 & 2,54 & 5,35 & 0,95 & 11,48 & 0,68 \\
\hline
\end{tabular}

Fonte: Adaptado de Cimento Itambé

Tabela 2. Características Físicas do Cimento Itambé CPII-Z 32

\section{Características Físicas}

\begin{tabular}{c|c|c|c|c|c|c|c|c|c|c}
\hline \multirow{2}{*}{$\begin{array}{c}\text { Exp. } \\
\text { Quente } \\
(\mathrm{mm})\end{array}$} & \multicolumn{2}{|c|}{$\begin{array}{c}\text { Tempo de } \\
\text { Pega (h:min) }\end{array}$} & $\begin{array}{c}\text { Cons. } \\
\text { Normal }\end{array}$ & $\begin{array}{c}\text { Blaine } \\
\left(\mathrm{cm}^{2} / \mathrm{g}\right)\end{array}$ & $\begin{array}{c}\text { \#200 } \\
(\%)\end{array}$ & \multirow{2}{*}{$\begin{array}{c}\# 325 \\
(\%)\end{array}$} & \multicolumn{4}{|c}{$\begin{array}{c}\text { Resistência } \\
\text { à Compressão (Mpa) }\end{array}$} \\
\cline { 2 - 7 } & Início & Fim & $(\%)$ & & & & 1 & 3 & 7 & 28 \\
\hline 0,36 & $03: 07$ & $03: 52$ & 26,3 & 3.589 & 3,1 & 13,78 & 11,9 & 24,6 & 31,4 & 40,4 \\
\hline
\end{tabular}

Fonte: Adaptado de Cimento Itambé

\subsection{Agregado Miúdo}

O agregado miúdo foi coletado no canteiro de obras da Universidade Tecnológica Federal do Paraná (UTFPR) e colocado em estufa para remoção da umidade. Após esta etapa, foram feitos os ensaios relacionados na Tabela 3 de acordo com as normas vigentes para caracterização de Agregados Miúdos.

\footnotetext{
* Contribuição técnica ao $69^{\circ}$ Congresso Anual da ABM - Internacional e ao 14ํㅡㄹ ENEMET - Encontro Nacional de Estudantes de Engenharia Metalúrgica, de Materiais e de Minas,21 a 25 de julho de 2014, São Paulo, SP, Brasil.
} 


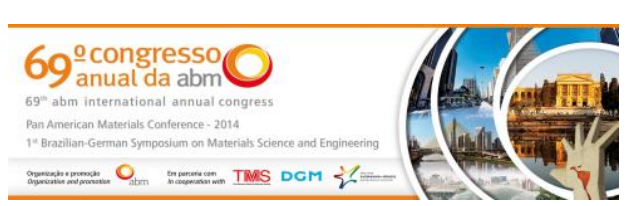

Tabela 3. Características do Agregado Miúdo

\begin{tabular}{|c|c|c|}
\hline ENSAIO & MÉTODO & RESULTADO \\
\hline Massa específica seca & NBR NM 52:2009 [12] & $2,63 \mathrm{~g} / \mathrm{cm}^{3}$ \\
\hline $\begin{array}{l}\text { Massa unitária no } \\
\text { estado solto }\end{array}$ & NBR NM 45:2006 [13] & $1,53 \mathrm{~g} / \mathrm{cm}^{3}$ \\
\hline Material pulverulento & NBR NM 46:2001 [14] & $3,2 \%$ \\
\hline $\begin{array}{l}\text { Composição } \\
\text { granulométrica }\end{array}$ & $\begin{array}{c}\text { NBR NM } \\
248: 2001[15]\end{array}$ & $\begin{array}{c}\text { Dimensão Máxima Característica: } \\
0,6 \mathrm{~mm} \\
\text { Módulo de finura: } 1,82\end{array}$ \\
\hline
\end{tabular}

A Figura 1 mostra a curva granulométrica do agregado miúdo usado na preparação dos corpos de prova.

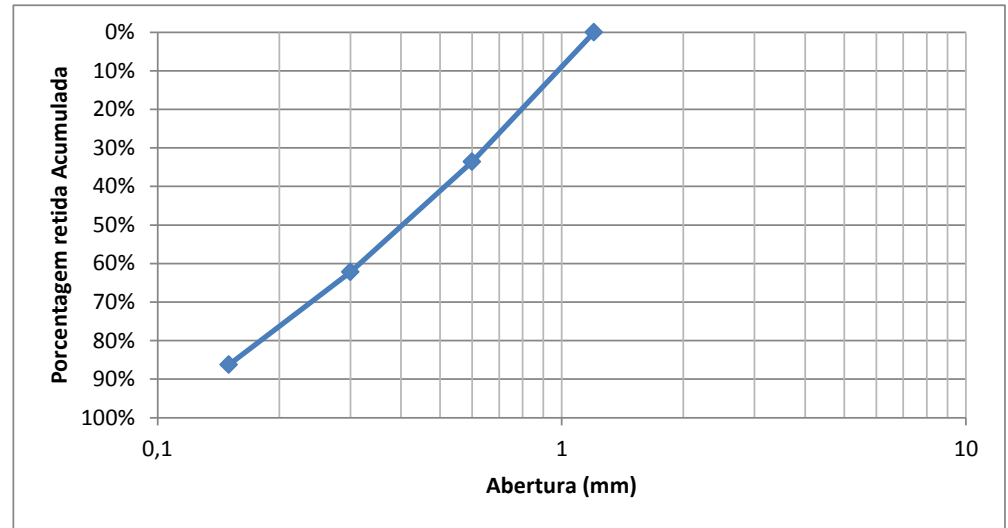

Figura 1. Curva granulométrica do agregado miúdo.

\subsection{Cal Hidratada}

A massa específica da cal $\mathrm{CH}$-III da marca Pinocal foi determinada a partir das recomendações da norma NBR 23:2001 [16] obtendo o resultado de $2,43 \mathrm{~g} / \mathrm{cm}^{3}$.

\subsection{Fibra de Vidro}

Para fazer a comparação da argamassa baritada com as argamassas convencionais, foi necessário o acréscimo de fibra de vidro na confecção das amostras das argamassas. A principal característica da utilização desta fibra é aumentar a resistência mecânica em peças sujeitas aos esforços de flexão.

A fim de se determinar o teor de fibras de vidro utilizadas na argamassa baritada, uma amostra foi peneirada através de uma abertura de $2,4 \mathrm{~mm}$ e o teor de fibras em relação à massa seca total da mistura foi determinada.

O percentual de fibra utilizado foi o mesmo recomendado pelos fabricantes de argamassas baritadas, ou seja, $0,04 \%$ em massa.

\subsection{Argamassa Baritada}

Os componentes da argamassa baritada apresentada pelo fabricante é mostrada na Tabela 4.

\footnotetext{
* Contribuição técnica ao 69ำ Congresso Anual da ABM - Internacional e ao 14ํㅡㄹ ENEMET - Encontro Nacional de Estudantes de Engenharia Metalúrgica, de Materiais e de Minas,21 a 25 de julho de 2014, São Paulo, SP, Brasil.
} 
Tabela 4. Componentes da argamassa baritada

\begin{tabular}{c|c}
\hline Areia quartsoza & $57,12 \%$ \\
\hline Sulfato de bário bruto & $28,56 \%$ \\
\hline Catalizador & $14,28 \%$ \\
\hline Fibra de vidro & $0,04 \%$ \\
\hline
\end{tabular}

\subsection{Determinação das Propriedades das Argamassas}

\subsubsection{Dosagem}

Foram ensaiadas argamassas mistas de revestimento com o traço "1:2:9". O teor de fibra de vidro foi fixado em $0,04 \%$ da massa do cimento utilizada. A quantidade de água para o traço de referência foi ajustada com o objetivo de se obter um índice de consistência fixo de $250 \pm 10 \mathrm{~mm}$ para a argamassa de referência.

\subsubsection{Propriedades no estado fresco}

As argamassas dosadas em laboratório foram confeccionadas utilizando os procedimentos descritos pela NBR 7215:1996 [17], em um misturador (Figura 2) de acordo as etapas descritas na Figura 3.

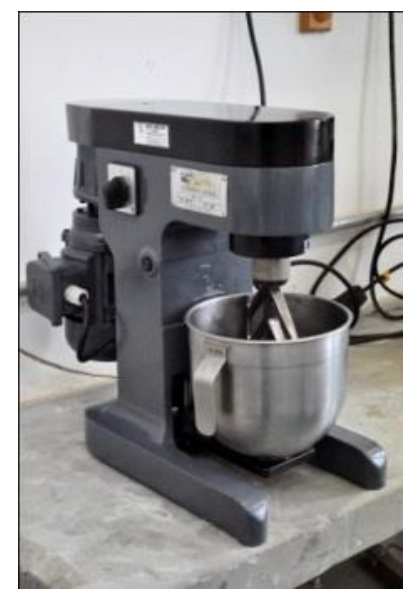

Figura 2. Misturador mecânico utilizado no ensaio.

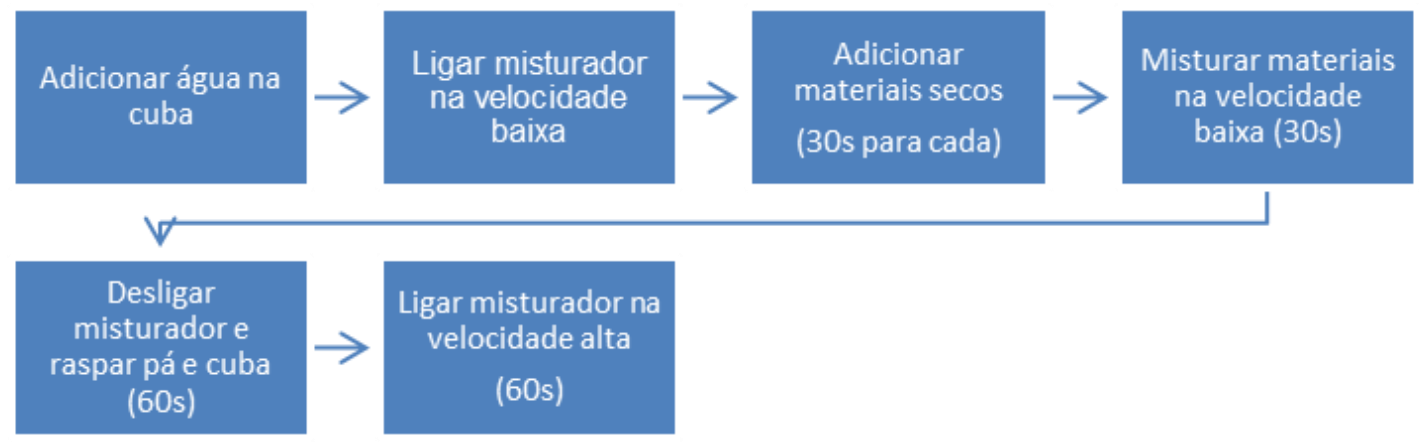

Figura 3. Procedimento de mistura adotado para argamassas [17].

\subsubsection{1 Índice de consistência}

$O$ índice de consistência foi obtido com base nas indicações da NBR 13276:2002 [18] na mesa de abatimento (flowtable). A Figura 4 mostra uma medida de consistência.

\footnotetext{
* Contribuição técnica ao 69ำ Congresso Anual da ABM - Internacional e ao 14ํㅡㄹ ENEMET - Encontro Nacional de Estudantes de Engenharia Metalúrgica, de Materiais e de Minas,21 a 25 de julho de 2014, São Paulo, SP, Brasil.
} 

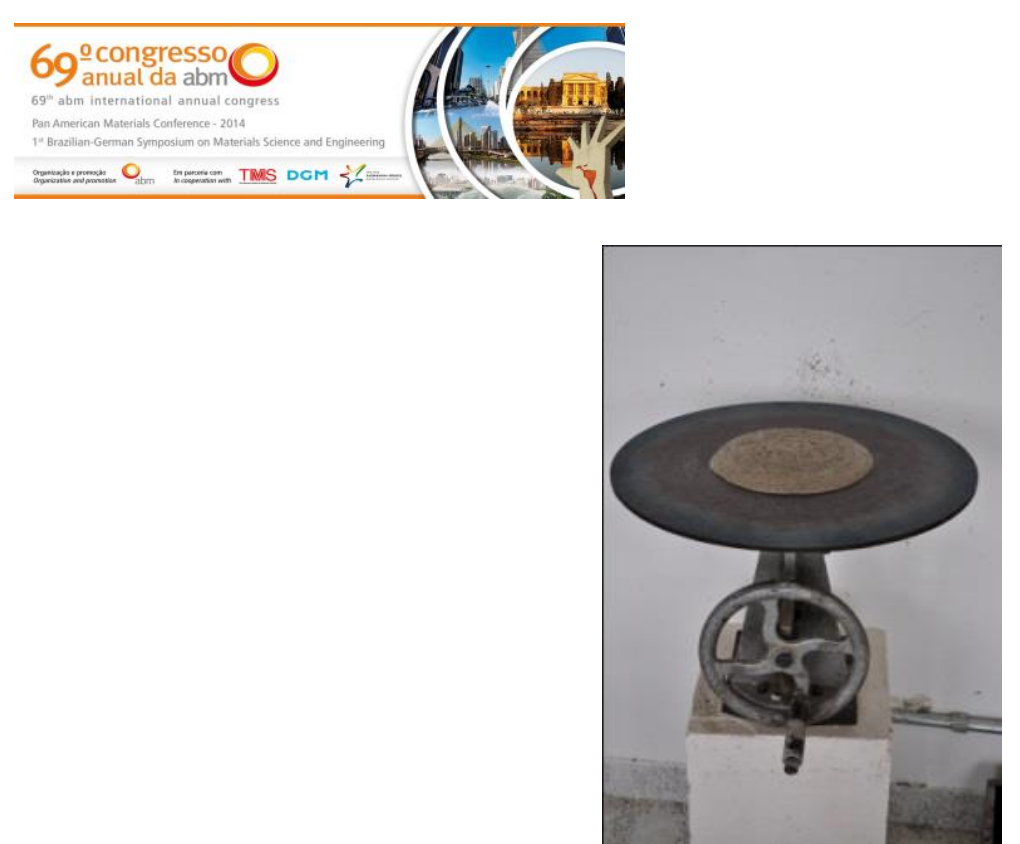

Figura 4. Medida de consistência.

\subsubsection{Densidade de massa e teor de ar incorporado}

A determinação da densidade de massa no estafo fresco foi realizada de acordo com a NBR 13278:2005 [19], através do preenchimento de um recipiente metálico, conforme Figura 5.

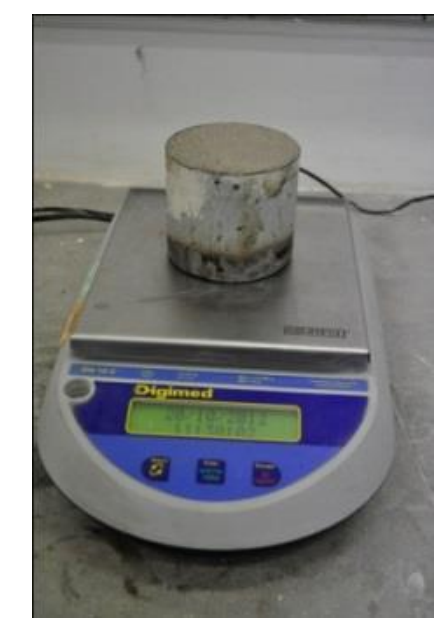

Figura 5. Densidade de massa no estado fresco.

\subsubsection{Propriedades no estado endurecido}

No estado endurecido foram realizados ensaios de resistência à compressão, resistência à tração na flexão, módulo de elasticidade dinâmico e módulo de elasticidade estático.

\subsubsection{Resistência à tração na flexão e compressão}

Foram moldados corpos-de-prova prismáticos $(40 \times 40 \times 160 \mathrm{~mm})$ com duas camadas e 30 quedas na mesa de adensamento de acordo com a NBR 13279:2005 [20].

As amostras foram desmoldadas após 48 horas e a cura dos corpos-de-prova foi seca ao ar. Foram realizados, aos 28 dias, rompimentos à flexão para verificação da resistência à tração da argamassa, e ensaios de resistência à compressão nas duas extremidades após o primeiro ensaio. O ensaio de resistência à flexão foi executado com um incremento força de $(50 \pm 10) \mathrm{N} / \mathrm{s}$ e os de resistência à compressão com incremento de $(500 \pm 50) \mathrm{N} / \mathrm{s}$. As Figuras 6 e 7 mostram os ensaios feitos nos corpos de prova.

\footnotetext{
* Contribuição técnica ao $69^{\circ}$ Congresso Anual da ABM - Internacional e ao 14ํㅡㄹ ENEMET - Encontro Nacional de Estudantes de Engenharia Metalúrgica, de Materiais e de Minas,21 a 25 de julho de 2014, São Paulo, SP, Brasil.
} 


\subsection{Avaliação da Atenuação da Radiação $X$ Através da Simulação Computacional}

Utilizando-se o Programa Xcom, foram simulados os coeficientes de atenuação das argamassas formuladas, utilizando a composição química das mesmas. Este procedimento segue a mesma metodologia do trabalho desenvolvido por FRIMAIO [8,5]. No intervalo de energia utilizado os valores de coeficientes de atenuação foram estimados a cada $0,01 \mathrm{keV}$. Com os valores de coeficiente de atenuação das argamassas formuladas e dos materiais de referência, foram construídas curvas de atenuação que auxiliaram no processo de confirmação dos melhores materiais.

\section{RESULTADOS E DISCUSSÃO}

\subsection{Características Mecânicas}

O índice de consistência foi obtido com base nas indicações da NBR 13276:2002 [18] na mesa de abatimento (flowtable), conforme mostra a Figura 9.

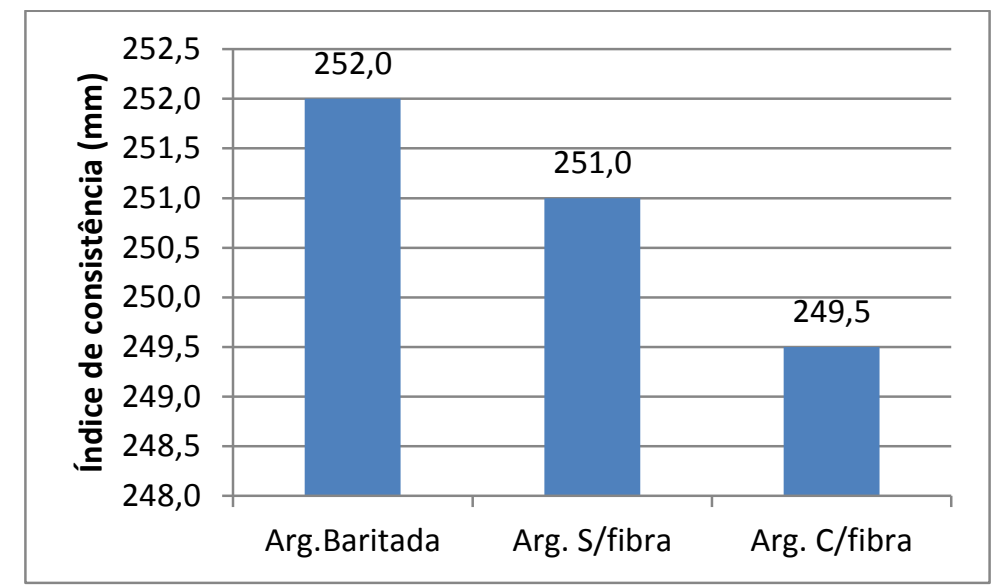

Figura 9. Variação do índice de consistência.

A variação da densidade de massa no estado fresco está representada na Figura 10.

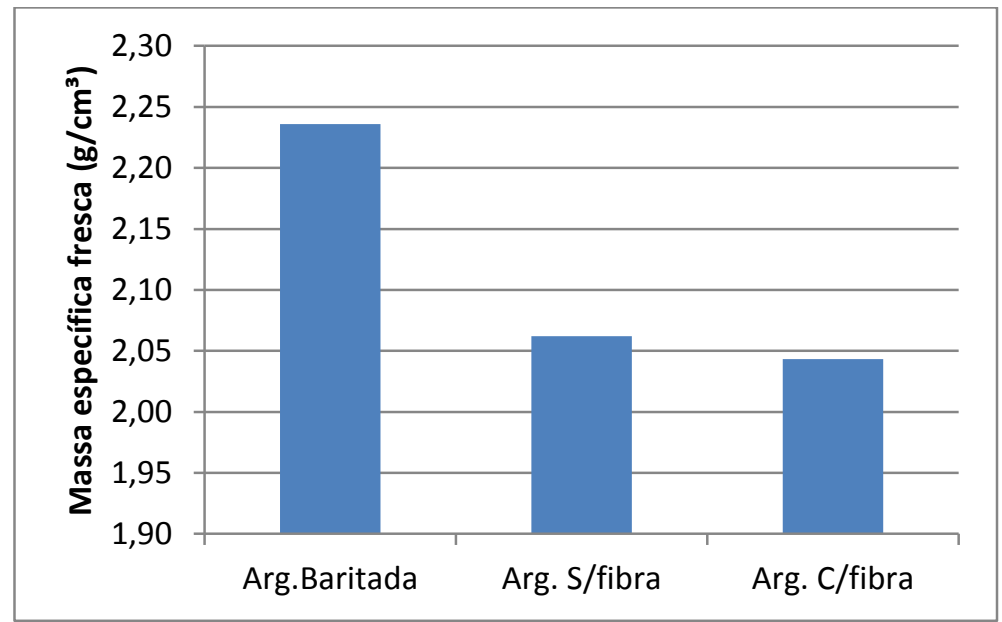

Figura 10. Variação da massa específica.

\footnotetext{
* Contribuição técnica ao $69^{\circ}$ Congresso Anual da ABM - Internacional e ao 14ํㅡㄹ ENEMET - Encontro Nacional de Estudantes de Engenharia Metalúrgica, de Materiais e de Minas,21 a 25 de julho de 2014, São Paulo, SP, Brasil.
} 
O índice de vazios e a absorção total estão apresentados na Figura 11.

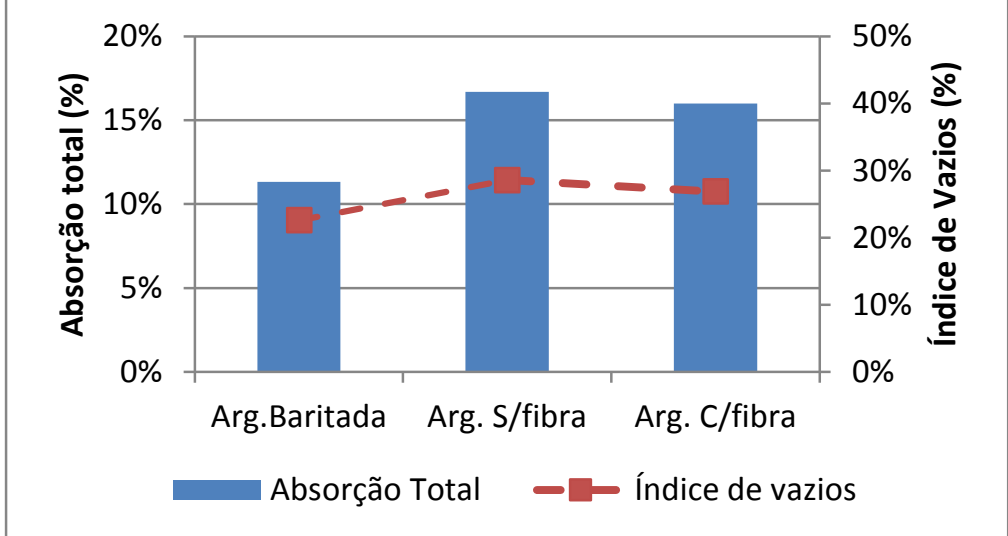

Figura 11. Índice de vazios e absorção total.

Foram desconsiderados os valores que se encontravam fora do desvio padrão calculado.

As resistências relativas à flexão e compressão das amostras estão mostradas na Figura 12.

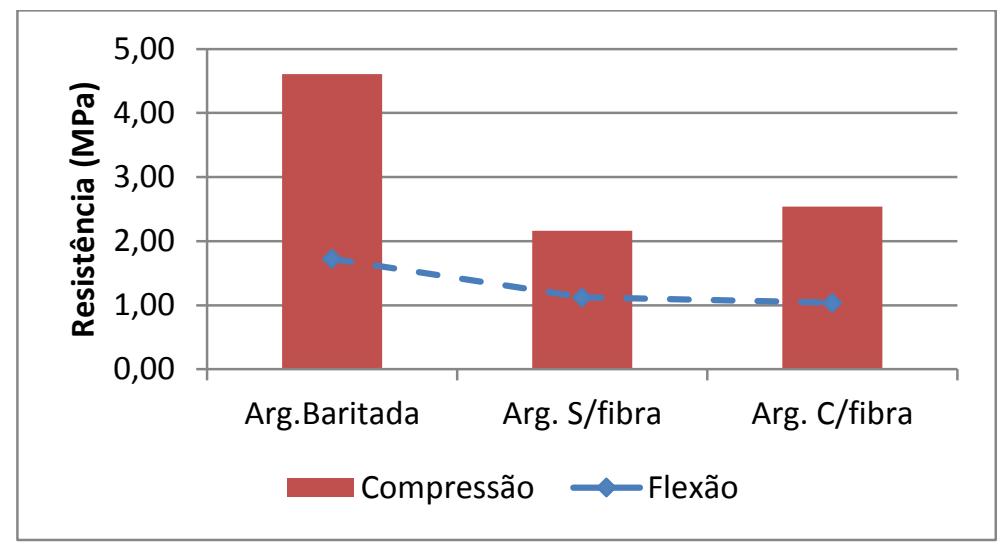

Figura 12. Ensaios de resistência mecânica.

A densidade de massa aparente no estado endurecido e o módulo de elasticidade dinâmico das argamassas estão apresentados na Figura 13.

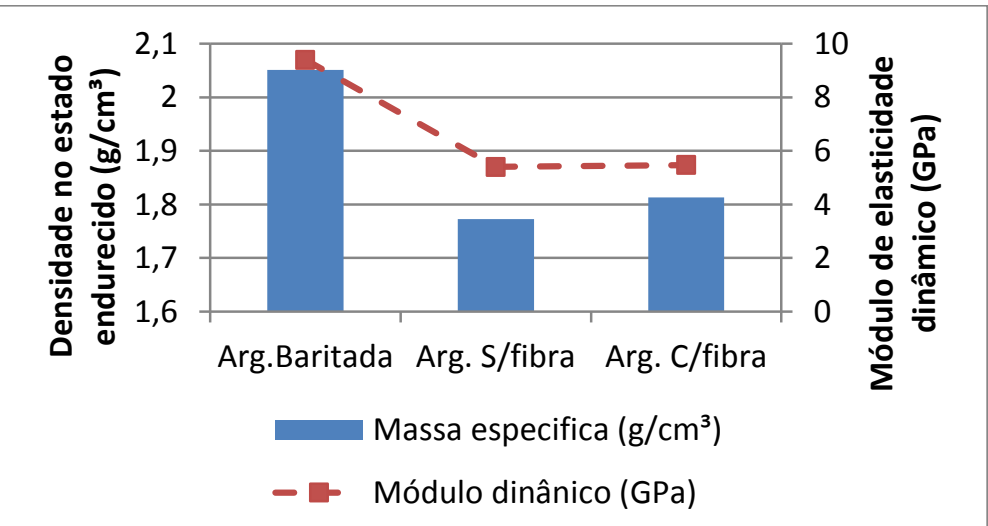

Figura 13. Densidade no estado endurecido e módulo de elasticidade dinâmico.

\footnotetext{
* Contribuição técnica ao $69^{\circ}$ Congresso Anual da ABM - Internacional e ao 14ํㅡㄹ ENEMET - Encontro Nacional de Estudantes de Engenharia Metalúrgica, de Materiais e de Minas,21 a 25 de julho de 2014, São Paulo, SP, Brasil.
} 


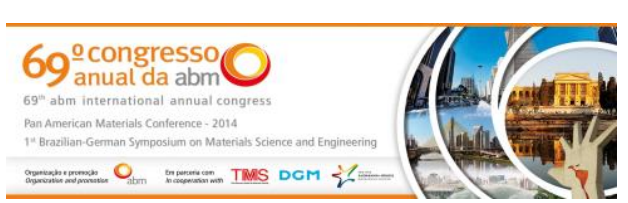

A Tabela 5 mostra o resumo das características mecânicas.

Tabela 5. Resumo das características mecânicas

\begin{tabular}{c|c|c|c|c|c|c|c|c}
\hline & $\begin{array}{c}\text { Índice de } \\
\text { Consistência } \\
(\mathrm{mm})\end{array}$ & $\begin{array}{c}\text { Massa } \\
\text { especifica } \\
\text { estado } \\
\text { fresco } \\
\left(\mathrm{g} / \mathrm{cm}^{3}\right)\end{array}$ & $\begin{array}{c}\text { Absorção } \\
\text { total } \\
(\%)\end{array}$ & $\begin{array}{c}\text { Índice } \\
\text { de } \\
\text { Vazios } \\
(\%)\end{array}$ & $\begin{array}{c}\text { Resistência } \\
\text { à } \\
\text { Compressão } \\
(\mathrm{MPa})\end{array}$ & $\begin{array}{c}\text { Resistência } \\
\text { à Tração } \\
(\mathrm{MPa})\end{array}$ & $\begin{array}{c}\text { Densidade } \\
\text { estado } \\
\text { endurecido } \\
\left(\mathrm{g} / \mathrm{cm}^{3}\right)\end{array}$ & $\begin{array}{c}\text { Módulo de } \\
\text { Elasticidade } \\
\text { dinâmico } \\
(\mathrm{GPa})\end{array}$ \\
\hline $\begin{array}{c}\text { Arg. } \\
\text { Baritada }\end{array}$ & 252,00 & 2,24 & 11 & 23 & 4,61 & 1,73 & 2,05 & 9,40 \\
\hline $\begin{array}{c}\text { Arg. } \\
\text { S/fibra }\end{array}$ & 251,00 & 2,06 & 17 & 29 & 2,16 & 1,12 & 1,77 & 5,40 \\
\hline $\begin{array}{c}\text { Arg. } \\
\text { C/fibra }\end{array}$ & 249,50 & 2,04 & 16 & 27 & 2,54 & 1,04 & 1,81 & 5,47 \\
\hline
\end{tabular}

\subsection{Análise Química por Fluorescência de Raios-X}

A análise química semiquantitativa detectou todos os elementos mais pesados que 0 flúor e presentes acima de 0,1\%. O tempo total de varredura foi de 6 minutos aproximadamente. As composições químicas das argamassas estão apresentadas na Tabela 6.

As análises químicas das argamassas serviram de dados para a simulação computacional - programa Xcom [11] que avalia as características de atenuação dos materiais.

Tabela 6. Composição semiquantitativa das argamassas

\begin{tabular}{c|c|c|c}
\hline \multicolumn{4}{|c}{ Composição semiquantitativa das argamassas } \\
\hline & Argamassa baritada (\%) & $\begin{array}{c}\text { Argamassa sem fibra } \\
(\%)\end{array}$ & $\begin{array}{c}\text { Argamassa com fibra } \\
(\%)\end{array}$ \\
\hline $\mathrm{SiO}_{2}$ & 52,7 & 58,8 & 57,9 \\
\hline $\mathrm{BaO}$ & 18,6 & & 16,3 \\
\hline $\mathrm{CaO}$ & 10,0 & 15,9 & 0,3 \\
\hline $\mathrm{SO}_{3}$ & 9,3 & 0,3 & 9,1 \\
\hline $\mathrm{CO}_{2}$ & 4,3 & 8,9 & 1,9 \\
\hline $\mathrm{Fe}_{2} \mathrm{O}_{3}$ & 2,9 & 1,7 & 3,9 \\
\hline $\mathrm{Al}_{2} \mathrm{O}_{3}$ & 1,1 & 3,7 & 8,0 \\
\hline $\mathrm{MgO}_{\mathrm{SrO}}$ & 0,3 & 8,0 & 1,2 \\
\hline $\mathrm{K}_{2} \mathrm{O}$ & 0,2 & & 0,3 \\
\hline $\mathrm{Na}_{2} \mathrm{O}$ & 0,2 & 1,3 & 0,1 \\
\hline $\mathrm{MnO}_{\mathrm{P}_{2} \mathrm{O}_{5}}$ & 0,2 & 0,3 & 0,9 \\
\hline $\mathrm{TiO}_{2}$ & 0,1 & 0,1 & 0,1 \\
\hline $\mathrm{ZrO}_{2}$ & 0,1 & & \\
\hline
\end{tabular}

\subsection{Aplicação do Modelo Matemático - Simulação no Programa Xcom}

A Figura 14 apresenta as curvas de atenuação em massa para os materiais de referência (chumbo sólido) e para as argamassas normais com e sem fibra de vidro e argamassa baritada, resultantes da simulação matemática do programa Xcom.

\footnotetext{
* Contribuição técnica ao 69ำ Congresso Anual da ABM - Internacional e ao 14ํㅡㄹ ENEMET - Encontro Nacional de Estudantes de Engenharia Metalúrgica, de Materiais e de Minas,21 a 25 de julho de 2014, São Paulo, SP, Brasil.
} 

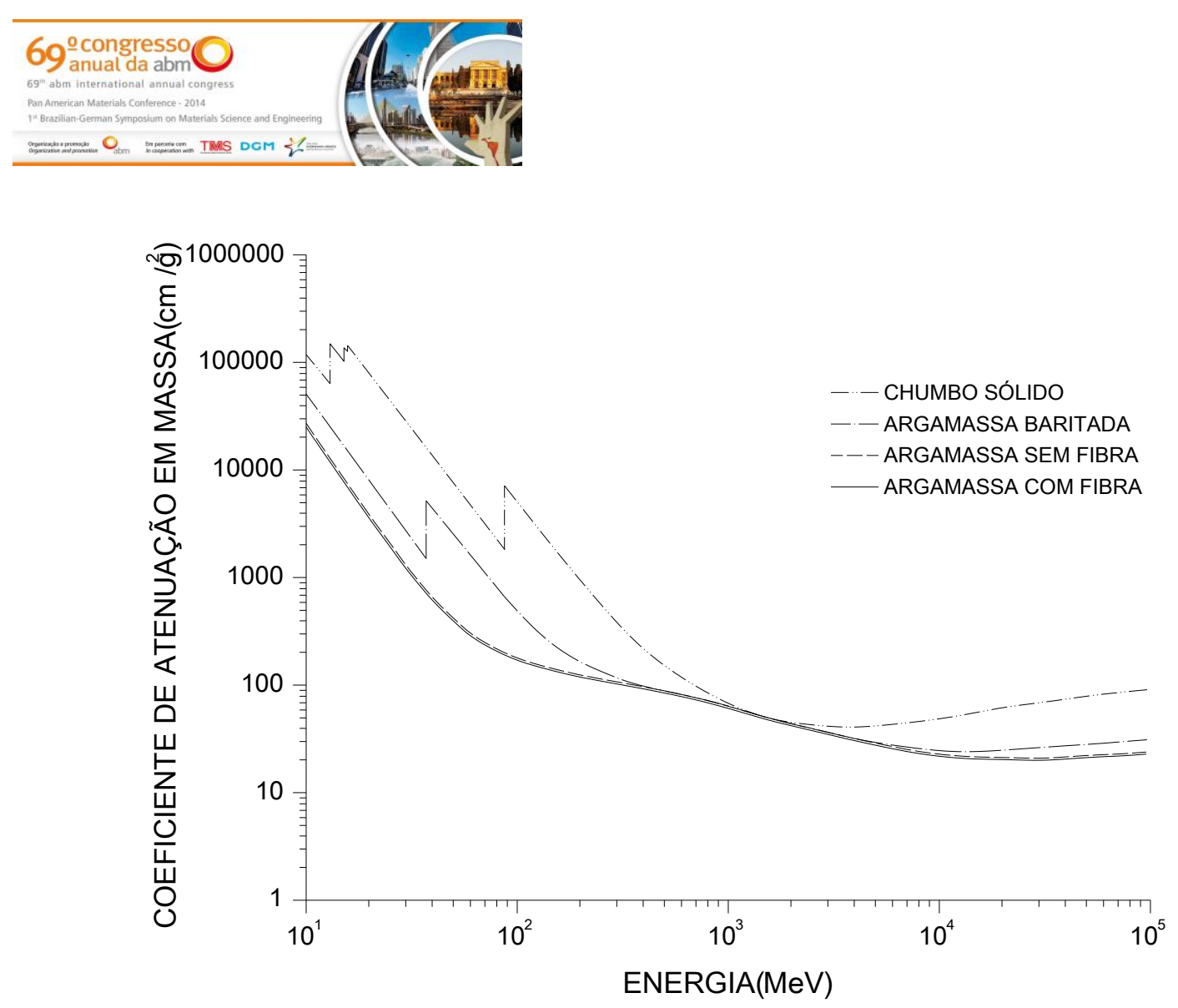

Figura 14. Curvas de Atenuação em Massa x Energia - Argamassas e material de referência (chumbo sólido).

A Tabela 7 apresenta os valores dos coeficientes de atenuação em massa para uma energia de $100 \mathrm{MeV}$.

Tabela 7. Coeficientes de atenuação em massa para os materiais ensaiados COEFICIENTE DE ATENUAÇÃO EM MASSA $\left(\mathrm{cm}^{2} / \mathrm{g}\right)$ para $100 \mathrm{MeV}$

\begin{tabular}{l|c}
\hline Chumbo sólido (referência) & $5,34 \times 10^{3}$ \\
\hline Argamassa baritada & $4,88 \times 10^{2}$ \\
\hline Argamassa sem fibra & $1,69 \times 10^{2}$ \\
\hline Argamassa com fibra & $1,68 \times 10^{2}$ \\
\hline
\end{tabular}

Avaliando as curvas de atenuação, pode-se confirmar qual é o material mais atenuante no que se refere à exposição de radiação $X$, sendo o chumbo sólido 0 material mais atenuante seguido da argamassa baritada, argamassa sem fibra de vidro e por último a argamassa com fibra de vidro.

Analisando o coeficiente de atenuação em massa de cada material, tomando-se como referência o chumbo sólido, conclui-se que a argamassa baritada atenua dez vezes menos que o chumbo e as argamassas, tanto com fibra e sem fibra de vidro, atenuam aproximadamente trinta vezes menos que o material de referência.

\section{CONCLUSÃO}

Mesmo trabalhando em escala de laboratório, a argamassa baritada ensaiada alcançou níveis de maior proteção, se comparada às argamassas com fibra e sem fibra de vidro, podendo ser usada como revestimento para proteção radiológica.

Tomando-se como referência o valor da densidade da argamassa baritada apresentada pelo fabricante $\left(3,2 \mathrm{~g} / \mathrm{cm}^{3}\right)$ e o valor obtido no laboratório $\left(2,24 \mathrm{~g} / \mathrm{cm}^{3}\right)$, pode-se concluir que a mesma terá uma resposta inferior, pois a diferença

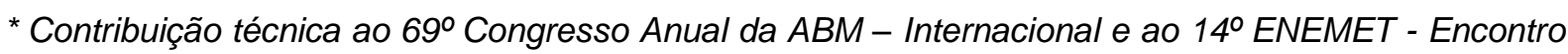
Nacional de Estudantes de Engenharia Metalúrgica, de Materiais e de Minas,21 a 25 de julho de 2014, São Paulo, SP, Brasil. 


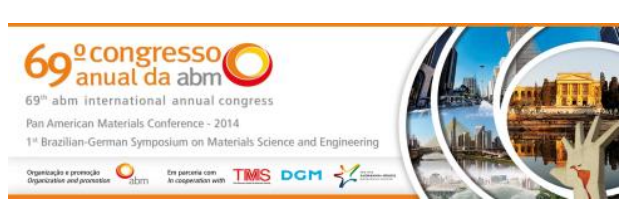

apresentada é na ordem de $40 \%$. As demais argamassas, por apresentarem densidades inferiores $\left(2,04 \mathrm{~g} / \mathrm{cm}^{3}\right)$, não são aconselhadas para esta finalidade.

As curvas de atenuação em massa, obtidas nesta pesquisa para os diversos materiais estudados, poderão servir de base comparativa em projetos de blindagens, bem como, banco de dados para programas computacionais destinados ao cálculo de barreiras de proteção.

\section{Agradecimentos}

Agradecemos a UTFPR pelo apoio através do Edital PROREC 02/2013UTFPR_EXTENSÃO.

\section{REFERÊNCIAS}

1 Carasek H. Argamassas Cap. 26. In: Isaia GC. Materiais de Construção Civil e Princípios de Ciência e Engenharia de Materiais. São Paulo: Ibracon; 2010.

2 Associação Brasileira de Normas Técnicas. NBR 13281: Argamassa para assentamento e revestimento de paredes e tetos - Requisitos. Rio de Janeiro; 2005.

3 Mohamed G, Roman HR, Rizatti E, Romagna R. Alvenaria Estrutural. In: Isaia GC. (org.). Materiais de construção civil e princípios de ciência e engenharia de materiais. São Paulo: Ibracon; 2010. p.1045-75.

4 Silva RP, Barros MSB, Pileggi RG, John VM. Avaliação do comportamento da argamassa no estado fresco através dos métodos de mesa de consistência, dropping ball e squeeze flow. In: Anais do VI Simpósio Brasileiro de Tecnologia de Argamassas; 2005; Florianópolis, Brasil.

5 Barros FS. Utilização de resíduo de chumbo em forma de pó em compósitos poliméricos e como revestimento em superfícies metálicas para serem aplicados em instalações radiológicas [tese de doutorado]. Curitiba: PIPE, UFPR; 2009.

6 Barros FS. Determinação das Propriedades de Atenuação de Tijolos Cerâmicos Maciços e Argamassas Baritadas para sua Utilização como Barreira de Proteção em Salas de Radiodiagnóstico [dissertação de mestrado]. Curitiba: CPGEI, CEFET-PR; 2001.

7 Artel BWH. A Tolerância dos Polímeros à Radiação - Efeitos da Radiação em Polímeros. Revista Plástico Moderno. agosto; 2000.

8 Frimaio A. Desenvolvimento de um Material Cerâmico para Utilização em Proteção Radiológica Diagnóstica [dissertação de mestrado]. São Paulo: IPEN, USP; 2006.

9 Hussain R, Zia-Ul-Haq, Mohammad D. A Study of the Shielding Properties of Poly Ethylene Glycol - Lead Oxide Composite. Radiation Physics, Journal of Islamic Academy of Sciences.1997;10(3):81-84.

10 Abdo E, Ali MAM, Ismail MR. Natural Fibre High-density Polyethylene and Lead Oxide Composites for Radiation Shielding. Radiation Physics and Chemistry. 2003;66(3):185195.

11 Xcom. Program national Institute of Standard Technology (NIST). [acesso em 17 fev. 2014]. Disponível em: http://physics.nist.gov/PhysRefData/Xcom/html/xcom1.html.

12 Associação Brasileira de Normas Técnicas. NBR NM 52: Agregado miúdo Determinação da massa específica e massa específica aparente. Rio de Janeiro, 2009.

13 Associação Brasileira de Normas Técnicas. NBR NM 45:2006: Agregados Determinação da massa unitária e do volume de vazios. Rio de Janeiro; 2006.

14 Associação Brasileira de Normas Técnicas. NBR NM 46:2003: Agregados Determinação do material fino que passa através da peneira $75 \mathrm{um}$, por lavagem. Rio de Janeiro; 2003.

15 Associação Brasileira de Normas Técnicas. NBR NM 248:2003: Agregados Determinação da composição granulométrica. Rio de Janeiro; 2003.

\footnotetext{
* Contribuição técnica ao $69^{\circ}$ Congresso Anual da ABM - Internacional e ao 14ํㅡㄹ ENEMET - Encontro Nacional de Estudantes de Engenharia Metalúrgica, de Materiais e de Minas,21 a 25 de julho de 2014, São Paulo, SP, Brasil.
} 


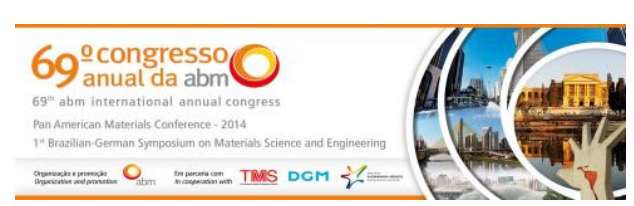

16 Associação Brasileira de Normas Técnicas. NM 23:2001: Cimento portland e outros materiais em pó - Determinação da massa específica - Determination of density. Rio de Janeiro; 2001.

17 Associação Brasileira de Normas Técnicas. NBR 7215:1996: Cimento Portland Determinação da resistência à compressão. Rio de Janeiro; 1996.

18 Associação Brasileira de Normas Técnicas. NBR 13276: Argamassa para assentamento e revestimento de paredes e tetos - Preparo da mistura e determinação do índice de consistência. Rio de Janeiro; 2005.

19 Associação Brasileira de Normas Técnicas. NBR 13278: Argamassa para assentamento e revestimento de paredes e tetos - Determinação da densidade de massa e do teor de ar incorporado. Rio de Janeiro; 2005.

20 Associação Brasileira de Normas Técnicas. NBR 13279: Argamassa para assentamento e revestimento de paredes e tetos - Determinação da resistência à tração na flexão e à compressão. Rio de Janeiro; 2005.

21 Associação Brasileira de Normas Técnicas. NBR 13280:2005: Argamassa para assentamento e revestimento de paredes e tetos - Determinação da densidade de massa aparente no estado endurecido. Rio de Janeiro; 2005.

22 Associação Brasileira de Normas Técnicas. NBR 15630:2008: Argamassa para assentamento e revestimento de paredes e tetos - Determinação do módulo de elasticidade dinâmico através da propagação de onda ultrassônica. Rio de Janeiro; 2008.

* Contribuição técnica ao 69ำ Congresso Anual da ABM - Internacional e ao 14ํㅡㄹ ENEMET - Encontro Nacional de Estudantes de Engenharia Metalúrgica, de Materiais e de Minas,21 a 25 de julho de 2014, São Paulo, SP, Brasil. 